\title{
Critérios para a implementação de práticas pedagógicas na formação inicial em educação física e implicações no conhecimento pedagógico do conteúdo dos futuros professores
}

CDD. 20.ed. 371.12

\author{
Daniel MARCON* \\ Amândio Braga dos Santos GRAÇA ${ }^{* *}$ \\ J uarez Vieira do NASCIMENTO***
}

*Curso de Educação Física, Universidade de Caxias do Sul. **Faculdade de Desporto, Universidade do Porto - Portugal. *Centro de Desportos, Universidade Federal de Santa Catarina

\section{Resumo}

0 conhecimento pedagógico do conteúdo é concebido como o responsável por transformar o conhecimento do conteúdo dos professores em conhecimento ensinável e compreensível pelos alunos. Para o desenvolvimento desse conhecimento na formação inicial em Educação Física, tem sido recomendada a aproximação entre os contextos de formação e da Educação Básica, especialmente por meio de estratégias de práticas pedagógicas. Diante disso, este ensaio teórico objetivou apresentar e discutir alguns critérios que subsidiem os programas de formação inicial em Educação Física nas tarefas de estruturação e de implementação dessas práticas pedagógicas. As informações analisadas permitem identificar cinco diferentes aspectos que podem orientar os programas de formação: local de realização (Instituição de Ensino Superior, escola ou espaços comunitários); quantidade de estudantes-professores ministrantes (grupos, trios, duplas ou individualmente); alunos participantes (colegas ou alunos da comunidade); quantidade de alunos participantes (um, dois, pequenos grupos ou a turma inteira); e quantidade de atividades ministradas (uma, uma sequência pedagógica ou uma unidade didática completa). A literatura sugere, ainda, que o alcance dos objetivos das práticas pedagógicas nos programas de formação inicial depende das concepções que os programas de formação, os professores-formadores e os estudantes-professores têm a respeito da participação dessas estratégias formativas na formação dos futuros professores de Educação Física. Acredita-se, pois, que esses cinco critérios contribuam para a implementação de diferentes modalidades de práticas pedagógicas, as quais permitirão ao conhecimento pedagógico do conteúdo atuar como interlocutor entre a base de conhecimentos para o ensino e o contexto de ensino e aprendizagem, o que potencializará o gradativo desenvolvimento do próprio conhecimento pedagógico do conteúdo e a formação docente dos futuros professores ao longo da formação inicial em Educação Física.

UnITERMos: Formação de professores; Docência; Preparação docente; Competências pedagógicas; Estratégias de ensino.

\section{Introdução}

A base de conhecimentos para o ensino engloba o conjunto de conhecimentos necessários ao professor (Cochran, King \& Deruiter, 1991; Grossman, 1990; Shulman, 1987). São exemplos de integrantes dessa base aqueles conhecimentos relativos aos alunos e suas características, ao conteúdo da matéria de ensino, às questōes pedagógicas e ao contexto que circunda a aprendizagem, acrescidos de uma compreensão integrada e integradora desses: o conhecimento pedagógico do conteúdo
(Cochran, King \& Deruiter, 1991; Grossman, 1990; Shulman, 1987).

As proposições de Shulman $(1986,1987)$ a respeito do conhecimento pedagógico do conteúdo estabeleceram uma nova etapa na investigação sobre a formação inicial e continuada de professores, abrindo caminho para que, ao longo dos anos subsequentes, vários autores (CHEN, 2004; GRAÇA, 1997, 2001; Graça \& Januário, 2000; GrifFin, Dodds \& Rovegno, 1996; Jenkins \& Veal, 2002; Ramos, 
Graça \& Nascimento, 2007; SChINCARIOL, 2002) aprofundassem os estudos relacionados ao processo de construção, desenvolvimento e utilização desse conhecimento em diferentes contextos de formação e de atuação docente na área de Educação Física.

Ao mesmo tempo, àquela definição inicial apresentada por SHULMAN $(1986,1987)$ foram sendo incorporados elementos que permitiram sua evolução e esclarecimento, sua ampliação e disseminação em diferentes áreas do conhecimento e sua adaptação e incorporação tanto à formação inicial dos estudantesprofessores - futuros professores - quanto à formação continuada e à atuação docente dos professores (Abell, 2008; Even, 1993; Kind, 2009; MarKS, 1990; Park, Jang, Chen \& Jung, 2010; Segall, 2004; Van Driel, Verloop \& De Vos, 1998).

Apoiando-se nesses estudos e se reportando especificamente ao processo de formação inicial de professores, o conhecimento pedagógico do conteúdo pode ser compreendido como aquele que o estudante-professor utiliza para, a partir dos seus objetivos, da realidade dos alunos e das características do contexto de ensino e aprendizagem, convocar, gerir e fazer interagir os conhecimentos da base de conhecimentos para o ensino, visando à adaptação, à transformação e à implementação do conhecimento do conteúdo a ser ensinado, de modo a torná-lo compreensível e ensinável aos alunos.

Para alcançar esses objetivos, estudos oriundos da área de Educação Física (Behets \& Vergauwen, 2006; Carreiro Da Costa, 1996; Crum, 2000; Griffin, Dodds \& Rovegno, 1996; MARCON, NASCIMENTO \& Graça, 2007; Nascimento, Ramos, Marcon, Sadd \& Collet, 2009; TANI, 1995) e de outras áreas do conhecimento (Calderhead \& Shorrock, 1997; Carter, 1990; Cochran, King \& Deruiter, 1991; FormosiNHO, 2001; Grossman \& MCDONALD, 2008; Lima \& Reali, 2002; Marques, 2000; Park \& Oliver, 2008; Perdigão, 2002; Pimenta, 2002; Reali \& Mizukami, 2002; ZEICHNER, 1993, 2010) têm ressaltado a importância da aproximação do contexto de formação com as realidades social e escolar, destacando a necessidade de levar os estudantes-professores a conhecerem e a se depararem, desde cedo na sua formação inicial, com dilemas e situações-problema inerentes à intervenção docente e profissional dos professores.

Essas discussões têm sido permeadas por posicionamentos que enfatizam as contribuições das práticas pedagógicas nesse processo (BEHETS \& VERGAUWEN, 2006; CALDERHEAD \& SHORROCK, 1997; Carreiro Da Costa, 1996; Crum, 2000; Fontana \& Guedes-Pinto, 2002; Formosinho, 2001; MARCon,
Nascimento \& Graça, 2007; Marques, 2000; NASCimENTO et al., 2009; Pimenta, 2002; WoOdS, GoCKarp \& Escamilla, 2000; Zeichner, 1993), à medida que possibilitam a constituição de situações de ensino e aprendizagem com diferentes características, que gradualmente vão inserindo o estudante-professor no mundo da docência e na profissão de professor. Conforme conclui WRIGHT (1999) em seus estudos a respeito da formação inicial em Educação Física, experiências anteriores ao estágio podem oferecer mais oportunidades aos estagiários, não apenas para implementar métodos de ensino e estratégias que lidem com essas questóes, mas também para possibilitar que os estagiários avaliem os padrões de comportamento de seus alunos de um modo mais real. [...] Essas estratégias permitirão que os estudantes assumam o papel de professor e antecipem problemas potenciais que eles possam vir a enfrentar durante sua prática pedagógica (p.65-6, tradução nossa).

Em idêntico sentido, Formosinho (2001) esclarece que a

prática pedagógica é a componente curricular da formação profissional de professores cuja finalidade explícita é iniciar os alunos no mundo da prática docente e desenvolver as competências práticas inerentes a um desempenho docente adequado e responsável (p.39).

TANI (1995) sintetiza a análise dessas questões ao afirmar que, na formação inicial em Educação Física, "a vivência prática desempenha um importante papel enquanto um mecanismo que possibilita a verificação 'experimental' do conhecimento no processo de sua aquisição" (p.20).

Nesse contexto, a literatura consultada (BEHETS \& Vergauwen, 2006; Fontana \& Guedes-Pinto, 2002; Grossman \& McDonald, 2008; Hegarty, 2000; Marcon, Nascimento \& GraÇA, 2007; Nascimento et al., 2009; TARdif, 2002; Wright, 1999; ZeICHNER, 2010) sugere que a incorporação das práticas pedagógicas pelos programas de formação inicial de professores potencializa o desenvolvimento do conhecimento pedagógico do conteúdo dos estudantes-professores ao longo do processo de formação, principalmente no período que antecede a realização dos estágios curriculares no fim dos cursos.

Entretanto, e apesar do avanço nas discussōes sobre o tema, ainda carecem de maior esclarecimento os critérios que podem ser utilizados pelos programas de formação inicial para planejar e implementar essas práticas pedagógicas, de modo a se elevar progressivamente o grau de exigência dos futuros professores 
e, principalmente, favorecer a construção do seu conhecimento pedagógico do conteúdo.

Esse é o cenário no qual se insere o presente ensaio, que tem como objetivos apresentar e discutir alguns critérios que subsidiem os programas de formação inicial em Educação Física no planejamento e na implementação das práticas pedagógicas, além de analisar as diferentes configuraçôes que podem assumir e os diversos momentos em que podem se inserir na estrutura curricular. $\mathrm{O}$ ensaio se propôs, ainda, de maneira transversal, a debater as possíveis repercussões da implementação das práticas pedagógicas tanto para os próprios programas de formação quanto e, fundamentalmente, para o processo de construção do conhecimento pedagógico do conteúdo dos futuros professores de Educação Física.

De modo a explorar a temática em questão, o ensaio foi dividido em duas etapas que se complementam. Enquanto a primeira se destina a apresentar e a discutir alguns critérios para a estruturação de diferentes modalidades de práticas pedagógicas, e que podem ser utilizados pelos programas de formação inicial em Educação Física, a segunda dedica-se a refletir sobre as influências das concepçôes dos estudantes-professores, dos professores-formadores e dos programas de formação no planejamento e na implementação das práticas pedagógicas.

\section{Modalidades de práticas pedagógicas}

Analisando as oportunidades oferecidas aos estudantes-professores de, ao longo da formação inicial, se defrontar com situações de ensino e aprendizagem com potencial de desenvolver seu conhecimento pedagógico do conteúdo, REALI e MizuKami (2002) explicam que

os chamados sistemas formais de ensino - nos quais os cursos de formação básica podem ser incluídos - envolvem geralmente situações de ensino e aprendizagem distantes daquelas circunstâncias de atuação prática, ocorrendo quase sempre de forma descontextualizada e episódica. As experiências caracterizadas pelos estágios ou práticas de ensino têm como marca, em geral, o artificialismo do ensino ministrado e da realidade do exercício profissional, na medida em que após um período longo de planejamento e preparação o aluno/futuro professor executa a sua "regência" numa circunstância tal em que muitas vezes os alunos da classe em que realiza o estágio são "orientados" a como se comportar (p.125).

Outras pesquisas (BeHETs \& VergaUWen, 2006; Cochran, King \& Deruiter, 1991; Crum, 2000; Formosinho, 2001; MARCON, NASCIMENTO \& GRAÇA, 2007; Nascimento et al., 2009; Pimenta, 2002; Reali \& Mizukami, 2002; TANi, 1995; Zeichner, 1993) têm apontado nessa direção e evidenciado tanto o artificialismo das práticas pedagógicas (realizadas nos programas de formação inicial de professores) quanto, nos casos em que ocorrem, o fato de possuírem característica episódica, esporádica e situada em momentos isolados do período de formação. Assim concebidas, as práticas pedagógicas têm poucas chances de "responder às reais necessidades de formação do professor, porque está posta em ações [...] pouco reais e até fictícias, descoladas da realidade" da futura atuação docente e profissional do estudante-professor (MACIEL, 2002, p.84).

Também refletindo a respeito dessa problemática, Perdigão (2002) destaca que, ao longo dos programas de formação inicial de professores,

a possibilidade do contato com eventos discrepantes [...] que constituam-se em elementos de contraposição às concepçōes pessoais dos estudantes ou ao seu poder explicativo [...] é bastante mais limitada no processo de formação inicial de professores. [...] A possibilidade de vivenciar, por um tempo substancial, uma experiência real de ensino que possibilite a participação do processo completo (planejamento, avaliação diagnóstica, ensino, avaliação da aprendizagem) é pequena. [...] Mesmo quando a possibilidade existe, ela é limitada em um tempo muito curto e, portanto, alguns problemas estão sempre presentes (p.286).

Na década de 90 (do séc. XX), TANi (1995) já apontava que, nos cursos de formação inicial de professores de Educação Física, os estudantesprofessores

raramente são [...] levados a praticar procedimentos didático-pedagógicos assumindo a função do professor ou mesmo levados a assistir às aulas como um observador e avaliador e não como praticante. Normalmente, oportunidades para esse tipo de experiências têm sido oferecidas 
apenas nas disciplinas de prática de ensino ou estágios supervisionados (p.25).

Em sua análise referente à presença de diferentes modalidades de práticas pedagógicas nos programas de formação inicial de professores, FormosinHo (2001) destaca dois critérios que contribuem para elucidar e ratificar essas questôes e podem, também, ser transpostos para a área de Educação Física: o primeiro critério proposto pelo autor diz respeito à existência, ou não, de um estatuto específico para a prática pedagógica inicial, o qual pode ser analisado desde pontos de vista mais academicistas até situações mais profissionalizantes de implementação das práticas pedagógicas pelos programas de formação inicial de professores:

(a) não existe no plano de estudos nenhuma

Prática Pedagógica Inicial, estando a prática pedagógica reduzida ao estágio; (b) a Prática Pedagógica Inicial inclui atividades de observação, mas não de responsabilidade direta pontual; e (c) a Prática Pedagógica Inicial segue todas as etapas atrás enunciadas - observação dos contextos, observação de aulas, desempenho pontual, prática docente acompanhada, entre outras atividades (Formosinho, 2001, p.43).

O segundo critério apresentado por ForMOsINHO (2001) está relacionado com a "gestão curricular da Prática Pedagógica Inicial como componente própria da formação de professores" (p.43), que, além de analisar as práticas pedagógicas desde situaçóes mais academicistas até situações mais profissionalizantes, também pode considerá-la tanto um apêndice da componente Ciências da Educação quanto ela própria ser uma componente de formação.

Por um lado, quando a prática pedagógica é interpretada como um apêndice da componente Ciências da Educação, ela

é transformada em disciplina específica desta área, enquadrada no calendário escolar normal, avaliada como uma disciplina (com algumas adaptações), distribuída no serviço docente disciplinar [e] realizada predominantemente nas salas de aula da instituição de formação (Formosinho, 2001, p.43).

Nesses casos, o autor ressalta que existe certa tendência de "normalizar" a prática pedagógica, "compartimentalizando-a disciplinarmente", em um processo pelo qual passará a ser "apenas uma disciplina um pouco diferente" das demais, podendo ser reduzida, inclusive, à simples "componente prática das disciplinas teóricas, o mero prolongamento destas disciplinas" (Formosinho, 2001, p.43).
Por outro lado, quando a própria prática pedagógica é considerada uma componente de formação dos estudantes-professores, ela "não aparece formatada em aulas, tem uma coordenação própria, uma gestão específica, objetivos, conteúdos e metodologias próprias e tempos próprios" (FormosinHo, 2001, p.43). Nesses casos, a realização das práticas pedagógicas "geralmente decorre antes ou depois do calendário docente da disciplina - ou no intervalo de semestres" e "predominantemente fora da instituição de formação - nas escolas e noutros contextos educativos" (Formosinho, 2001, p.43). Conforme conclui o autor, o "desenvolvimento adequado da Prática Pedagógica pressupõe, obviamente, que ela assuma o formato autônomo e não seja considerada apenas um apêndice da componente de Ciências da Educação" (Formosinho, 2001, p.44).

Nessa perspectiva, WoOds, Goc KarP e EscAMILLA (2000) afirmam que os programas de formação inicial de professores necessitam mudar de um modelo de transferência de conhecimento tradicional, no qual estratégias de ensino eficazes, testadas e aprovadas, são relatadas e expostas aos professores em formação inicial e praticadas por eles, para um modelo em que professores em formação inicial explorem ativamente, em um contexto, vários aspectos da base de conhecimentos para o ensino e comecem a tomar algumas decisões sobre as implicações que suas descobertas têm sobre eles e seus alunos (p.37, tradução nossa).

Diante do panorama desenhado pelos estudos revisados, o desafio que se coloca aos programas de formação inicial em Educação Física é, justamente, o de superar os problemas apontados e transformar suas concepções a respeito das práticas pedagógicas, passando a interpretá-las como ricas oportunidades para potencializar a estruturação da base de conhecimentos e a construção do conhecimento pedagógico do conteúdo dos futuros professores. Concebendoas sob esse prisma e como uma componente de formação dos estudantes-professores, os programas de formação inicial em Educação Física passam a assumir a responsabilidade de estabelecer estratégias e mecanismos que efetivamente possibilitem a realização de diferentes modalidades de práticas pedagógicas, com diferentes estruturas e objetivos e que sejam inseridas em diferentes momentos do processo de formação inicial.

Todavia, apesar do relativo consenso sobre a necessidade de aproximar o contexto de formação inicial do contexto da Educação Básica, como 
condição fundamental para o pleno desenvolvimento do conhecimento pedagógico do conteúdo dos estudantes-professores (BARBOSA-RINALDI, 2008; Behets \& Vergauwen, 2006; Calderhead \& SHOrROCK, 1997; ENNIS, 1994; GIMENO SACRISTÁN, 1995; Graber, 1995; Hegarty, 2000; Marcon, Nascimento \& GraÇA, 2007; MEIRIEU, 2002; PÉrEZGÓMEZ, 1995; PiMENTA, 2002; WoOds, Goc Karp \& ESCAMILLA, 2000; WRIGHT, 1999), o que se observa na literatura são poucas sugestôes a respeito das estratégias mais indicadas para efetivar essa aproximação.

Em outras palavras, não são comuns na literatura proposiçôes que contemplem direta e especificamente nem critérios que orientem e viabilizem a estruturação de modalidades de práticas pedagógicas com diferentes características, objetivos e níveis de exigência, nem mesmo estratégias e momentos de implementação das práticas pedagógicas nos programas de formação inicial em Educação Física. São exemplos de estudos que acenam com algumas proposiçôes nesse sentido, mesmo que advindos de diferentes disciplinas, aqueles realizados por BEHETS e Vergaumen (2006), Formosinho (2001), Marcon, Nascimento e Graça (2007), Park e Oliver (2008), e Reali e Mizukami (2002).

Sendo assim, buscou-se reunir alguns critérios com o objetivo de instigar a reflexão a respeito dos possíveis encaminhamentos para o planejamento e a implementação das práticas pedagógicas pelos programas de formação inicial de professores de Educação Física, sem a pretensão de abarcar todas as modalidades de práticas pedagógicas ou de esgotar a discussão sobre o tema. A consideração de cada um desses critérios pode aumentar as chances tanto de se planejar e implementar diversas modalidades de práticas pedagógicas, com diferentes estruturas e níveis de exigência, quanto de se situar e justificar a presença de cada uma dessas modalidades de prática pedagógica dentro do programa de formação inicial em Educação Física.

Isso quer dizer que, com base nas particularidades de cada instituição e nas especificidades e concepções de cada programa de formação inicial e de suas respectivas unidades de ensino, as práticas pedagógicas podem se distribuir horizontalmente por todo o processo de formação inicial dos futuros professores de Educação Física a partir, por exemplo, da resposta a cada uma das cinco perguntas:

1) em que local?, já que a prática pedagógica pode ser realizada nas dependências da Instituição de Ensino Superior (IES) ou na comunidade, seja na escola, seja em locais públicos específicos para recreação e lazer;

2) quem ministra?, pois a prática pedagógica pode ser ministrada, por exemplo, por um grupo, por um trio ou por uma dupla de estudantesprofessores, bem como por um estudante-professor individualmente;

3) para quais alunos?, visto que a prática pedagógica pode ser ministrada para os próprios colegas ou para alunos da comunidade escolar;

4) para quantos alunos?, considerando que a prática pedagógica pode ser ministrada apenas para um aluno, para alguns alunos ou para toda a turma de alunos; e

5) sob qual estrutura?, já que a prática pedagógica pode ser composta por uma única atividade, por uma sequência pedagógica ou por uma unidade didática completa.

A síntese desses cinco critérios para o planejamento e a implementação das práticas pedagógicas, bem como a relação intrínseca dos critérios entre si, os diferentes níveis de exigência das práticas pedagógicas e as diversas etapas do programa de formação inicial de professores, é apresentada na FIGURA 1. 


\begin{tabular}{|c|c|c|c|c|c|c|}
\hline \multirow{2}{*}{\multicolumn{2}{|c|}{ Fonte: Marcon (2011) }} & \multicolumn{3}{|c|}{$\begin{array}{l}\text { LOCAL*/ } \\
\text { ALUNOS* }\end{array}$} & & \\
\hline & & $\begin{array}{c}\text { IES/ } \\
\text { colegas }\end{array}$ & $\begin{array}{c}\text { IES/ } \\
\text { alunos em } \\
\text { idade } \\
\text { escolar }\end{array}$ & $\begin{array}{l}\text { Escolas/ } \\
\text { alunos em } \\
\text { idade } \\
\text { escolar }\end{array}$ & & \\
\hline \multirow{3}{*}{ 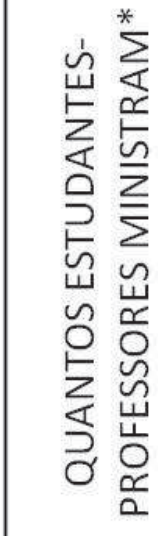 } & Grupos & 1 & 2 & 3 & $\begin{array}{l}\text { Um/ } \\
\text { dois }\end{array}$ & \multirow{3}{*}{ 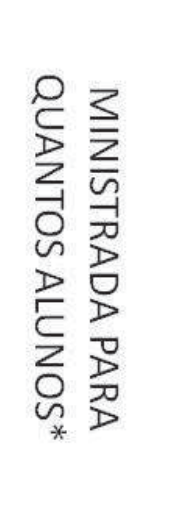 } \\
\hline & $\begin{array}{l}\text { Trios/ } \\
\text { duplas }\end{array}$ & 2 & 3 & 4 & $\begin{array}{c}\text { Pequenos } \\
\text { grupos }\end{array}$ & \\
\hline & Individual & 3 & 4 & 5 & $\begin{array}{l}\text { Toda a } \\
\text { turma }\end{array}$ & \\
\hline \multirow{2}{*}{\multicolumn{2}{|c|}{$\begin{array}{l}\text { NÍVEL DE EXIGÊNCIA DAS } \\
\text { PRÁTICAS PEDAGÓGICAS: } \\
\text { 1- baixo } \\
2 \text { - de baixo a moderado } \\
3 \text { - moderado } \\
4 \text { - de moderado a alto } \\
5 \text { - alto }\end{array}$}} & Uma & $\begin{array}{c}\text { Uma } \\
\text { sequência } \\
\text { pedagógica }\end{array}$ & $\begin{array}{c}\text { Uma } \\
\text { unidade } \\
\text { didática } \\
\text { completa }\end{array}$ & \multirow{2}{*}{\multicolumn{2}{|c|}{$\begin{array}{l}\text { ETAPAS DO PROGRAMA } \\
\text { DE FORMAÇÃO INICIAL: } \\
\text { 1-ingresso } \\
\text { 2- primeiros semestres } \\
\text { 3-intermediária } \\
\text { 4- avançada } \\
\text { - estágios curriculares }\end{array}$}} \\
\hline & & \multicolumn{3}{|c|}{$\begin{array}{c}\text { ESTRUTURA } \\
\text { QUANTAS ATIVIDADES* }\end{array}$} & & \\
\hline
\end{tabular}

* Critérios para o planejamento e a implementação de diferentes modalidades de práticas pedagógicas em distintas etapas do programa de formação inicial de professores

FIGURA 1 - Evolução do nível de exigência das práticas pedagógicas na formação inicial de professores.

O entrecruzamento dos eixos vertical e horizontal da FIGURA 1 por sobre os números de 1 até 5 leva à identificação dos critérios a serem adotados para a seleção de cada modalidade de prática pedagógica, do nível de exigência de cada uma delas, do momento em que estará inserida do curso e, consequentemente, da maneira como se estruturará. O número 1 , por exemplo, que representa um nível de exigência baixo e a etapa de ingresso na formação inicial, remete a uma prática pedagógica ministrada pelos estudantesprofessores na IES para os próprios colegas (quadro superior do eixo vertical) e que será composta de uma única atividade (quadro inferior do eixo vertical), ao mesmo tempo que será ministrada por um grupo de estudantes-professores (quadro à esquerda do eixo horizontal) para um ou dois alunos - nesse caso os próprios colegas (quadro à direita do eixo horizontal). Por outro lado, o número 5, que representa um nível de exigência alto e a etapa da formação inicial relativa aos estágios curriculares, remete a uma prática pedagógica ministrada pelos estudantes-professores nas escolas da Educação Básica para alunos em idade escolar (quadro superior do eixo vertical) e que será composta por uma unidade didática completa (quadro inferior do eixo vertical), a qual será ministrada individualmente (quadro à esquerda do eixo horizontal) para toda a turma de alunos (quadro à direita do eixo horizontal).

A configuração das práticas pedagógicas, a partir desses cinco critérios e sua inserção ao longo do programa de formação inicial em Educação Física, estará 
atrelada às concepções epistemológicas e pedagógicas dos programas de formação, bem como à maneira pela qual interpretam a participação das práticas pedagógicas na construção do conhecimento pedagógico do conteúdo e, por consequência, na constituição da personalidade docente dos futuros professores.

De qualquer forma, se espera que os programas de formação inicial em Educação Física destinem espaço suficiente, ao longo do curso, assim como os professores-formadores em suas respectivas disciplinas, para que os estudantes-professores possam transitar pelas diferentes configurações das práticas pedagógicas, ou seja, ministrar aulas em grupo e individualmente; na própria IES e na escola; para seus colegas e alunos em idade escolar; para pequenos grupos e turmas inteiras; e desde uma única atividade até unidades didáticas completas.

Como afirmam diferentes autores (BeHETs \& Vergauwen, 2006; Cochran, King \& Deruiter, 1991; Formosinho, 2001; García, 1995; Graber, 1995; Marcon, Nascimento \& Graça, 2007; Nascimento et al., 2009; Wright, 1999), tanto uma única estratégia pedagógica, ministrada em grupo para os colegas na própria IES, quanto uma aula completa, ministrada individualmente para alunos na escola, terão diferentes e importantes parcelas de contribuição na estruturação da base de conhecimentos e na construção e no desenvolvimento do conhecimento pedagógico do conteúdo dos estudantes-professores e, consequentemente, na sua formação acadêmica, docente e profissional.

Uma vez contempladas nos projetos pedagógicos e planejadas pelos professores-formadores, cada uma dessas modalidades de práticas pedagógicas poderá ser implementada gradualmente em momentos específicos do programa de formação em Educação Física e, na consideração da estrutura da base de conhecimentos e do constructo do conhecimento pedagógico do conteúdo que tenham como suporte, impor, de maneira progressiva e cada vez mais, exigências aos estudantes-professores.

Nesse caso, se forem comparados entre si o desempenho docente do futuro professor de Educação Física naquela única estratégia pedagógica ministrada em grupo para os colegas na própria IES, nas primeiras disciplinas curriculares do programa de formação; e naquela aula completa ministrada individualmente para alunos na escola nas disciplinas curriculares que antecedem os estágios curriculares; poderão ser observadas importantes evoluções na sua base de conhecimentos e no seu conhecimento pedagógico do conteúdo.

Esse processo de inserção gradual dos estudantesprofessores nos contextos de atuação docente e profissional do professor durante o programa de formação inicial é analisado por FormosinHo (2001), ao explicar que

a Prática Pedagógica Inicial (isto é, a prática pedagógica pré-estágio) geralmente desenvolve-se de modo gradual - inicia-se pela observação de contextos (comunitários e escolares), continua com a observação de aulas e de crianças, assume depois a forma de prática docente pontual nas turmas dos professores cooperantes. Este é um esquema típico baseado na passagem gradual dos contextos para a sala de aula e da observação para o desempenho (p.43, grifo do autor).

Independentemente de sua estrutura, configuração, objetivos e momentos de inserção nos programas de formação inicial em Educação Física, todas essas práticas pedagógicas contêm elementos fundamentais que contribuem de forma permanente para a análise e reformulação da base de conhecimentos e a reestruturação do conhecimento pedagógico do conteúdo dos estudantes-professores, como "a problematização, a intencionalidade para encontrar soluções, a experimentação metodológica [e] o enfrentamento de situações de ensino complexas". (PimentA, 1997, p.59).

Conforme explicam Graber (1995) e Wright (1999) em seus estudos, na medida em que o futuro professor de Educação Física experienciar cada uma das modalidades de prática pedagógica e, justamente em função da diversidade de estímulos que as compõem, o conhecimento pedagógico do conteúdo será submetido a diferentes processos de avaliação, sob vários focos e que utilizarão critérios e níveis de exigência específicos. Essa avaliação analisará a sequência de procedimentos implementados pelo conhecimento pedagógico do conteúdo para cumprir as funçôes que lhe cabem na própria prática pedagógica, assim como seus reflexos no processo de formação docente dos estudantes-professores (CALDERHEAD \& SHORROCK, 1997; García, 1995; Meirieu, 2002; Nascimento et al., 2009; Perdigão, 2002; Wright, 1999).

Um aspecto a destacar é que cada uma dessas modalidades de prática pedagógica dará conta de suas respectivas atribuições na formação dos estudantes-professores desde que esteja devidamente situada, fundamentada e justificada no programa de formação, de modo a garantir que esse processo se desenvolva de maneira gradativa, permanente e consistente (BeHETS \& VergauWEN, 2006; CALDERHEAD \& SHORrock, 1997; Formosinho, 2001; Wright, 1999; ZEICHNER, 1993).

Contudo e, independentemente da forma como as práticas pedagógicas serão estruturadas, 
propostas e implementadas ao longo da formação inicial em Educação Física, é fundamental que se leve em consideração as concepções dos estudantesprofessores, dos professores-formadores e dos próprios programas de formação a seu respeito, já que cada uma dessas concepções tem potencial para determinar o sucesso ou o fracasso de tais estratégias no alcance de seus objetivos.

\section{Influências das concepções na implementação das práticas pedagógicas}

A preocupação com as concepções que os futuros professores de Educação Física têm a respeito das práticas pedagógicas se explica, inicialmente, à medida que a existência de interpretações equivocadas por sua parte pode representar sintomas de problemas na consolidação das concepções dos programas de formação e/ou do próprio corpo docente (BEHETS \& Vergauwen, 2006; Chen, 2004; Sebren, 1995).

A falta de um posicionamento claro por parte dos programas de formação de professores quanto à justificativa da adoção das práticas pedagógicas, às suas diferentes estruturas e aos momentos em que serão inseridas no período da formação inicial, tem sido apontado (Calderhead \& Shorrock, 1997; Sebren, 1995) como um dos principais responsáveis pelas dificuldades apresentadas pelos estudantes-professores na sua relação com o conhecimento pedagógico do conteúdo. De acordo com os estudos realizados por Amade-Escot (2000) e Graber (1995), alguns desses problemas se referem às dificuldades em definir o conhecimento pedagógico do conteúdo, em identificá-lo no programa de formação e, até mesmo, em reconhecêlo como um dos conhecimentos fundamentais para a atuação docente na área de Educação Física.

Concepções deturpadas a respeito das próprias práticas pedagógicas podem ser verificadas por meio da resistência de alguns estudantes-professores quando essas estratégias são apresentadas pelos professoresformadores como integrantes do processo de formação em determinadas disciplinas. Diferentes estudos (ALTET, 2001; AMADE-EsCot, 2000; CALDERHEAD \& SHORROCK, 1997; Crum, 2000; Marcon, Nascimento \& GraÇA, 2007; Marques, 2000; Nascimento et al., 2009; SCHÖN, 1995; TANI, 1995) têm demonstrado que a proposta das práticas pedagógicas gera esse tipo de reação por parte dos futuros professores - de Educação Física e de outras disciplinas - principalmente porque aulas ministradas aos colegas representam situações fictícias e descoladas da realidade; porque dar aulas para alunos da comunidade implica aceitar o desafio de se submeter a situações abertas, imprevisíveis e, provavelmente, de difícil gestão; porque, em ambos os casos, haverá necessidade de dedicar um tempo extraclasse para o planejamento das aulas; porque eles serão os atores principais, responsáveis pelo planejamento, pela execução e avaliação de situações de ensino e aprendizagem; e porque a avaliação à qual estarão submetidos levará em conta sua atuação na prática docente, o que potencializa as dificuldades naturais de todos os aspectos anteriores.

Situações como essas, bem como nos casos em que os futuros professores de Educação Física participam das práticas pedagógicas somente para cumprir a tarefa, como se fosse uma obrigação imposta pelo professor ministrante da disciplina, ou como mera aplicação prática de sequências pedagógicas prontas e descontextualizadas (GrAÇA, 1999; Marcon, Nascimento \& GraÇA, 2007; TANI, 1995), desvirtuam a essência das práticas pedagógicas e fazem com que o estudante-professor não se dê conta do protagonismo dessas estratégias no processo de construção do seu conhecimento pedagógico do conteúdo (DARIDO, 1995; Graber, 1995).

Diante desse cenário, um dos principais desafios dos programas de formação inicial em Educação Física é a desmistificação das práticas pedagógicas por parte dos estudantes-professores, para que deixem de interpretá-las como imposições dos professoresformadores ou unicamente como um requisito necessário para sua aprovação em determinada disciplina curricular (MARCON, 2005; NASCIMENTO et al., 2009).

Conforme sugere a literatura consultada (AMADEEscot, 2000; Graber, 1995; Perrenoud, 2002b; SCHÖN, 1995; ZEICHNER, 1993), a meta é a construção de interpretações positivas sobre as práticas pedagógicas, para que os estudantes-professores passem a considerá-las ricas oportunidades para avaliar e aprimorar seu conhecimento pedagógico do conteúdo, para errar enquanto há tempo, enquanto ainda estão experimentando a docência dentro da IES, juntos com os colegas e com o apoio dos professores-formadores.

Um dos caminhos mais rápidos e objetivos para isso é convencer os futuros professores de Educação Física de que lhes é mais vantajoso compartilhar suas dificuldades com os colegas que estão na mesma 
situação que eles e com os professores-formadores do que com pessoas alheias a esse contexto e de que o ambiente da formação inicial proporciona o momento e o local mais apropriados para que as dificuldades, os medos e as incertezas aflorem e sejam trabalhados.

Ao analisar essa questão, MEIrIEU (2002) reproduz um trecho descrito por Cifali que, por sua riqueza, clareza e relação íntima com o tema, merece destaque. Para o pleno desenvolvimento do conhecimento pedagógico do conteúdo dos futuros professores por meio das práticas pedagógicas e das reflexões a seu respeito, é necessário, de acordo com o autor,

partir do ocorrido. Subtrair-se de uma situação, expô-la, falar dela, compartilhá-la sem temor e, com isso, entrever o que foi fixado ou o que foi muito centrado. Abdicar de sua onipotência e deixar cair a máscara do idealismo. Avançar na incompreensão, desatar a angústia e a incerteza. Designar o limite. Observar, descrever, não ficar de fora de mensurar sua própria dimensão. Compreender um pouco, aceitar a parte que permanece incompreensível. Formular questões. Concordar em perder-se e depois, com o tempo, construir referências. Cultivar o desejo de busca e, ao mesmo tempo, de formar-se (CIFALI, 1994, citado por Meirieu, 2002, p.284).

Assim, para que sejam alcançados a construção do conhecimento pedagógico do conteúdo dos futuros professores de Educação Física e os objetivos de formação docente e profissional a partir das práticas pedagógicas, é fundamental que os estudantesprofessores aceitem cometer erros, considerem o erro inerente ao aprendizado, assumam riscos e administrem suas incertezas.

Como apontam diferentes estudos (AlaRCÃo, 1997; Caires, 2001; Calderhead \& Shorrock, 1997; GIMENO SACRISTÁN, 1995; LibÂNEO, 1997; Molina NeTO \& Molina, 2002; Sebren, 1995; Valli \& RennerTARIEV, 2002), o tratamento positivo dessas questóes por parte dos professores-formadores e do próprio programa de formação encaminhará os estudantes-professores ao reconhecimento da importância de se exporem de diferentes maneiras, de dialogarem com seus pares, de trocarem ideias e informações relacionadas à prática pedagógica e de participarem ativamente de debates no meio acadêmico e fora dele.

Os próprios estudantes-professores perceberão, nesse caso, que é muito melhor que seus pontos fracos sejam descobertos nas aulas, na IES, do que quando estiverem na escola, sozinhos e diante de uma turma de alunos. Os futuros professores de Educação Física passarão a interpretar as práticas pedagógicas, fundamentalmente aquelas realizadas no começo da formação inicial, justamente como oportunidades para errar e admitirão que o erro faz parte do aprendizado e que contribui para a construção de novos conhecimentos e para o aprimoramento do seu conhecimento pedagógico do conteúdo, tal como alega a literatura relativa à formação de professores (BEHETS \& VERGAUWEN, 2006; Gimeno SACRISTÁN, 1995; LiBÂNEO, 1997; Meirieu, 2002; Perrenoud, 2002a; SCHÖn, 1995).

$\mathrm{O}$ que se espera dos futuros professores de Educação Física é, portanto, o maior engajamento possível em todas as etapas e modalidades de práticas pedagógicas, seja antes, durante ou depois de sua realização, seja na IES ou na escola, seja com os colegas ou com os alunos da comunidade, e que passem a interpretá-las como valiosas oportunidades para estabelecer pontes entre teoria e prática, e para agregar valor a sua formação docente e profissional. Dessa forma, como sugerem diferentes autores (Alarcão, 1997; Behets \& VergauWen, 2006; Calderhead \& Shorrock, 1997; Carreiro Da Costa, 1996; Chen, 2004; Perrenoud, 2002a; Pimenta \& Lima, 2004; Sebren, 1995; Zeichner, 1993), os estudantes-professores poderão construir uma base de conhecimentos e um suporte psicológico e intelectual cada vez mais sólido e que lhes permitirá envolver-se em cada uma das diferentes modalidades de práticas pedagógicas de maneira consciente, crítica e com conhecimento de causa.

Ao mesmo tempo, as práticas pedagógicas passam a constituir um espaço para que sejam manifestadas, além dos conhecimentos construídos até o momento, as diferentes concepções do estudante-professor, suas opiniōes e seus pensamentos, já que,

em educação, não existe um saber-fazer desligado de implicações de valor, de consequências sociais, de pressupostos sobre o funcionamento dos seres humanos, individualmente ou em grupo, de opções epistemológicas acerca do conhecimento que se transmite (GIMENO SACRISTÁN, 1995, p.82).

Conforme for a participação do estudante-professor na aula que está ministrando, poderão ser percebidas, em maior ou em menor medida, suas concepções epistemológicas e pedagógicas, suas concepções de ensino e de aprendizagem, suas concepções de aluno e de professor e, inclusive, suas concepções de sociedade e de mundo (DARIDO, 1995; GIMENO SACristán, 1995; MeIrIeU, 2002; PerdigĀo, 2002; Setton, 2002; Thiry-Cherques, 2006). Além disso, ao ministrar uma aula ou uma unidade didática para um grupo de alunos, o futuro professor manifesta, até determinado ponto, não apenas os conhecimentos 
em sua base de conhecimentos, seu conhecimento pedagógico do conteúdo e suas concepçōes, mas reflete, também, a influência ou não das concepções do próprio programa de formação e dos professoresformadores na sua formação docente, acadêmica e profissional. (Gimeno SACRISTÁN, 1995; Graber, 1995; Marcelo, 1998; Sebren, 1995; Segall, 2004).

Em razão disso, as práticas pedagógicas passam a configurar relevantes oportunidades para que o próprio programa de formação inicial em Educação Física seja visualizado, analisado e avaliado. Isso é possível à medida que o estudante-professor revela, por meio do seu desempenho docente nas práticas pedagógicas, a incidência, na sua própria formação docente e profissional, de concepções (epistemológica, pedagógica, de aprendizagem e de avaliação, por exemplo) tanto do projeto pedagógico do curso e das suas unidades constituintes quanto dos professores-formadores (AMADE-ESCOT, 2000; Behets \& Vergauwen, 2006; Formosinho, 2001).

Por consequência, as práticas pedagógicas permitem que os professores-formadores reavaliem suas estratégias pedagógicas e, até mesmo, revejam suas próprias concepçōes sobre os processos de construção do conhecimento pedagógico do conteúdo e de formação docente e profissional dos estudantes-professores (Behets \& Vergauwen, 2006; Darido, 1995; Montalvāo \& Mizukami, 2002; Segall, 2004).

Reforçando essas questões, Segall (2004) destaca a necessidade de observar não apenas como os professores-formadores concebem a ideia do conhecimento pedagógico do conteúdo para eles próprios, mas também como cada um deles se integra no programa de formação inicial de professores e faz refletir as suas próprias concepçōes e as concepções do programa de formação nas práticas pedagógicas dos estudantes-professores.

A partir disso, e alicerçadas nas concepções do projeto pedagógico do curso e dos professores-formadores, as práticas pedagógicas contribuem para encaminhar os estudantes-professores a um nível de conscientização que favorece o reconhecimento da importância dessas estratégias no programa de formação inicial em Educação Física e a identificação de seus reflexos no seu conhecimento pedagógico do conteúdo e na qualificação de sua formação docente e profissional.

Ao invés da mera transmissão de informações em pacotes fechados e impessoais, os programas de formação inicial em Educação Física necessitam desestabilizar a estrutura organizacional da base de conhecimentos dos estudantes-professores, instigando-os ao questionamento e à dúvida por meio de práticas pedagógicas que gerem inquietação e desejo pela descoberta, apurando seu poder de argumentação e seu senso crítico.

De modo geral, a participação das práticas pedagógicas - com o objetivo de aprimorar a atuação docente - possibilita aos futuros professores de Educação Física ampliar e fortalecer os conhecimentos em sua base de conhecimentos; reestruturar suas concepçóes sobre o processo de ensino e aprendizagem e sobre a presença das práticas pedagógicas no programa de formação inicial; e delinear e consolidar, progressivamente, seu conhecimento pedagógico do conteúdo e seu perfil docente e profissional.

\section{Considerações finais}

Para viabilizar a construção do conhecimento pedagógico do conteúdo dos futuros professores e alcançar os objetivos dos programas de formação inicial em Educação Física, a literatura consultada ressalta a necessidade de que se estruturem e implementem diferentes modalidades de práticas pedagógicas, distribuindo-as por todo o período de formação dos estudantes-professores.

Entretanto, diante da relativa dificuldade em identificar claramente critérios que subsidiem essas estruturação e implementação, o presente ensaio se propôs a contribuir nesse sentido a partir das proposiçóes de diferentes autores. Alguns desses critérios dizem respeito, pois, 1) ao local de realização das práticas pedagógicas (IES, escola ou espaços comunitários); 2) a quantos estudantes-professores ministrarão a prática pedagógica (grupos, trios, duplas ou individualmente); 3) a quem serão os alunos (colegas ou alunos da comunidade); 4) a quantos serão os alunos (um, dois, pequenos grupos ou a turma inteira); e 5) a quantas atividades serão ministradas (uma, uma sequência pedagógica ou uma unidade didática completa).

Um aspecto destacado nos estudos analisados foi o de que os estudantes-professores, ao longo do programa de formação inicial em Educação Física, tenham a oportunidade de transitar por diferentes configurações das práticas pedagógicas, ou seja, ministrar aulas em grupo e individualmente; na própria IES e na escola; para seus colegas e alunos em idade escolar; para pequenos grupos e para toda a turma; e desde uma única atividade até a unidade didática completa. 
Uma vez que os programas de formação e os professores-formadores constituem elementos centrais no processo de planejamento e de implementação das práticas pedagógicas, é fundamental que sejam consideradas as suas concepçōes a respeito do papel desempenhado por essas estratégias formativas para a construção do conhecimento pedagógico do conteúdo dos futuros professores de Educação Física. Essas questôes têm grande potencial para determinar o caráter das práticas pedagógicas e, até mesmo, a sua presença ou não no processo formativo dos futuros professores. A consideração atenta das concepçôes dos programas de formação, dos professoresformadores e dos estudantes-professores poderá decidir, portanto, até que ponto o conhecimento pedagógico do conteúdo dos estudantes-professores terá condiçóes de atuar como interlocutor entre a base de conhecimentos para o ensino e o contexto de ensino e aprendizagem, processo considerado pela literatura como imprescindível para qualificar a formação docente e a profissional dos futuros professores na formação inicial em Educação Física.

É enaltecida a necessidade de que os programas de formação inicial em Educação Física, efetivamente, incorporem as práticas pedagógicas em seu cotidiano, acompanhadas de criteriosas e constantes reflexões e "feedbacks" por parte dos professores-formadores, e que as assumam como uma de suas principais estratégias para a construção do conhecimento pedagógico do conteúdo e para a formação docente e profissional dos futuros professores ao longo do curso. Essas questōes evidenciam o estreito vínculo estabelecido entre as práticas pedagógicas implementadas pelos programas de formação inicial e o processo de construção do conhecimento pedagógico do conteúdo dos futuros professores de Educação Física.

Das análises realizadas neste ensaio teórico, podese extrair, também, que o conhecimento pedagógico do conteúdo ainda representa um campo de estudos pouco explorado na área concernente à Educação Física, principalmente no âmbito nacional. Ao mesmo tempo, merece destaque a importância que estudos recentes têm conferido às práticas pedagógicas no interior dos programas de formação inicial de professores - de Educação Física e de outras áreas do conhecimento - sugerindo, inclusive, que essa é a direção para onde a investigação tende a caminhar rapidamente nos próximos anos.

\begin{abstract}
Criteria for implementation of pedagogical practices in physical education teacher education and implications in pedagogical content knowledge of prospective teachers

Pedagogical content knowledge is conceived as responsible for transforming teachers' content knowledge into teachable knowledge comprehensible to students. For the entire development of the pedagogical content knowledge during Physical Education teacher education, the approximation between contexts of formation and basic education, especially through strategies of pedagogical practices, has been recommended. Considering these concerns, this theoretical essay has aimed to present and discuss some criteria which subsidize formation programs in Physical Education in tasks for structuring and implementing these pedagogical practices. The information analyzed allows to identify five different aspects which can orientate formation programs: place of execution (higher education institution, school or community spaces); number of prospective teachers who will give the pedagogical practice (groups, trios, pairs or individually); students participating in the activities (classmates or community students); number of students participating (one, two, small groups or the whole class); and the number of activities which will be given (one, a pedagogical sequence, or a complete teaching unit). Literature also suggests that the achievement of pedagogical practices goals in prospective formation programs depends on conceptions that formation programs, teacher educators, and prospective teachers have concerning the participation of these forming strategies in the formation of future Physical Education teachers. Therefore, it is believed these five criteria may contribute for the implementation of different modalities of pedagogical practices which will allow pedagogical content knowledge to function as interlocutor between the knowledge base for teaching and the teaching and learning context, which will maximize both gradual development of pedagogical content knowledge itself and prospective teachers' professional and teaching formation during Physical Education teacher education programs.
\end{abstract}

UnITERMS: Teaching formation; Pedagogical competences; Teaching strategies; Knowledge base for teaching. 


\section{Referências}

ABELL, S. K. Twenty years later: does pedagogical content knowledge remain a useful idea? International Journal of Science Education, London, v.30, n.10, p.1405-16, 2008. Disponível em: <http://www.informaworld. com/10.1080/09500690802187041>. Acesso em: 15 set. 2010.

ALARCÃO, I. Contribuição da didática para a formação de professores: reflexões sobre o seu ensino. In: PIMENTA, S. G. (Org.). Didática e formação de professores: percursos e perspectivas no Brasil e em Portugal. São Paulo: Cortez, 1997. p.159-90.

ALTET, M. As competências do professor profissional: entre conhecimentos, esquemas de ação e adaptação, saber analisar. In: PAQUAY, L.; PERRENOUD, P.; ALTET, M.; CHARLIER, É. (Orgs.). Formando professores profissionais. Quais estratégias? Quais competências? Porto Alegre: Artmed, 2001. p.23-35.

AMADE-ESCOT, C. The contribution of two research programs on teaching content: "pedagogical content knowledge" and "didactics of physical education". Journal of Teaching in Physical Education, Champaign, v.20, n.1, p.78-101, 2000. BARBOSA-RINALDI, I. P. Formação inicial em Educação Física: uma nova epistemologia da prática docente. Revista Movimento, Porto Alegre, v.14, n.3, p.185-207, 2008. Disponível em: <http://www.seer.ufrgs.br/index.php/Movimento/ article/view/2431/4183>. Acesso em: 21 set. 2009.

BEHETS, D.; VERGAUWEN, L. Learning to teach in the field. In: KIRK, D.; MacDONALD, D.; O' SULLIVAN, M. (Org.). Handbook of physical education. London: Sage, 2006. p.407-24.

CAIRES, S. Vivências e percepçóes do estágio no ensino superior. Minho: Grupo de Missão para a Qualidade do Ensino Aprendizagem/UM, 2001.

CALDERHEAD, J.; SHORROCK, S.B. Understanding teacher education: case studies in the professional development of beginning teachers. London: Falmer Press, 1997.

CARREIRO DA COSTA, F. Formação de professores: objectivos, conteúdos e estratégias. In: CARREIRO DA COSTA, F.; CARVALHO, L.M.; ONOFRE, M.S.; DINIZ, J.A.; PESTANA, C. (Orgs.). Formação de professores em educação física: concepções, investigação, prática. Lisboa: Edições FMH, 1996. p.9-36.

CARTER, K. Teachers knowledge and learning to teach. In: SIKULA, R.H.M.H.J. (Org.). Handbook of research on teacher education. New York: MacMillan, 1990. p.291-310.

CHEN, W. Learning the skill theme approach: salient and problematic aspects of pedagogical content knowledge. Education, [S.1.], v.125, n.2, p.194-212, 2004.

COCHRAN, K.F.; KING, R.A.; DERUITER, J.A. Pedagogical content knowledge: a tentative model for teacher preparation. In: ANNUAL MEETING OF THE AMERICAN EDUCATIONAL RESEARCH ASSOCIATION, 1991, Chicago. Proceedings... Chicago: AERA, 1991.

CRUM, B. Funções e competências dos professores de educação física: conseqüências para a formação inicial. Boletim da Sociedade Portuguesa de Educação Física, Lisboa, v.1, n.23, p.61-76, 2000.

DARIDO, S.C. Teoria, prática e reflexão na formação profissional em Educação Física. Motriz: Revista da Educação Física, Rio Claro, v.1, n.2, p.124-8, 1995.

ENNIS, C. Knowledge and beliefs underlying curricular expertise. Quest, Champaign, v.46, n.2, p.164-75, 1994.

EVEN, R. Subject-matter knowledge and pedagogical content knowledge: prospective secondary teachers and the function concept. Journal for Research in Mathematics Education, Washington, v.24, n.2, p.94-116, 1993.

FONTANA, R.A.C.; GUEDES-PINTO, A.L. Trabalho escolar e produção do conhecimento. In: SHIGUNOV NETO, A.; MACIEL, L.S.B. (Orgs.). Desatando os nós da formação docente. Porto Alegre: Mediação, 2002. p.6-22.

FORMOSINHO, J. A formação prática dos professores: da prática docente na instituição de formação à prática pedagógica nas escolas. Revista Portuguesa de Formação de Professores, Lisboa, v.1, p.37-54, 2001.

GARCÍA, C.M. A formação de professores: novas perspectivas baseadas na investigação sobre o pensamento do professor. In: NÓVOA, A. (Org.). Os professores e a sua formação. Lisboa: Dom Quixote, 1995. p.53-76.

GIMENO SACRISTÁN, J. Consciência e ação sobre a prática como libertação profissional dos professores. In: NÓVOA, A. (Org.). Profissão professor. Porto: Porto, 1995. p.63-92.

GRABER, K.C. The influence of teacher education programs on the beliefs of student teachers: general pedagogical knowledge, pedagogical content knowledge, and teacher education course work. Journal of Teaching in Physical Education, Champaign, v.14, n.2, p.157-78, 1995.

GRAÇA, A. O conhecimento do professor de educação física. In: BENTO, J.O.; GARCIA, R.; GRAÇA, A. (Orgs.). Contextos da pedagogia do desporto. Lisboa: Livros Horizonte, 1999. p.167-263. 
. O conhecimento pedagógico do conteúdo: o entendimento entre a pedagogia e a matéria. In: GOMES, P.B.; GRAÇA, A. (Orgs.). Educação física e desporto na escola: novos desafios, diferentes soluções. Porto: FCDEF-UP, 2001. p.107-20. O conhecimento pedagógico do conteúdo no ensino do basquetebol. 1997. $331 \mathrm{f}$. Tese (Doutorado em Ciências do Desporto) - Faculdade de Desporto, Universidade do Porto, Porto, 1997.

GRAÇA, A.; JANUÁRIO, C. Pedagogical content knowledge: a summary of the literature. In: CARREIRO-DA-COSTA, F.; DINIZ, J.A.; CARVALHO, L.M.; ONOFRE, M.S. (Orgs.). Research on teaching and research on teacher education: proceedings of the Lisbon AIESEP International Seminar, 1996. Cruz Quebrada: FMH, 2000. p.80-6.

GRIFFIN, L.; DODDS, P.; ROVEGNO, I. Pedagogical content knowledge for teachers: integrate everything you know to help students learn. The Journal of Physical Education, Recreation \& Dance, Reston, v.67, n.9, p.58-61, 1996. Disponível em: <http://find.galegroup.com/gtx/infomark.do?\&contentSet=IAC-Documents\&type=retrieve\&tabID=T002\&prodId=A ONE\&docId=A18988206\&source=gale\&srcprod=AONE\&userGroupName=ucs\&version=1.0>. Acesso em: 30 ago. 2010. GROSSMAN, P. The making of a teacher: teacher knowledge and teacher education. New York: Teachers College Press, 1990. GROSSMAN, P.; McDONALD, M. Back to the future: directions for research in teaching and teacher education. American Educational Research Journal, Washington, v.45, n.1, p.184-205, 2008. Disponível em: <http://aer.sagepub.com/ content/45/1/184>. Acesso em: 14 set. 2010.

HEGARTY, S. Teaching as a knowledge-based activity. Oxford Review of Education, Oxford, v.26, n. 3/4, p.45165, 2000. Disponível em: <http://search.ebscohost.com/login.aspx?direct=true\&db=aph\&AN=3893569\&site=ehostlive\&scope=site $>$. Acesso em: 14 set. 2009.

JENKINS, J.M.; VEAL, M.L. Preservice teachers' PCK development during peer coaching. Journal of Teaching in Physical Education, Champaign, v.22, n.1, p.49-68, 2002.

KIND, V. Pedagogical content knowledge in science education: perspectives and potential for progress. Studies in Science Education, Leeds, v.45, n.2, p.169-204, 2009. Disponível em: <http://www.informaworld.com/10.1080/03057260903142285>. Acesso em: 15 set. 2010.

LIBÂNEO, J.C. Educação, pedagogia e didática - o campo investigativo da pedagogia e da didática no Brasil: esboço histórico e buscas de identidade epistemológica e profissional. In: PIMENTA, S.G. (Org.). Didática e formação de professores: percursos e perspectivas no Brasil e em Portugal. São Paulo: Cortez, 1997. p.77-129.

LIMA, S.M.; REALI, A.M. O papel da formação básica na aprendizagem profissional da docência (aprende-se a ensinar no curso de formação básica?). In: MIZUKAMI, M.G.; REALI, A.M. (Orgs.). Formação de professores, práticas pedagógicas e escola. São Carlos: EdUFSCar, 2002. p.217-36.

MACIEL, L.S.B. A investigação como um dos saberes docentes na formação inicial de professores. In: SHIGUNOV NETO, A.; MACIEL, L.S.B. (Orgs.). Desatando os nós da formação docente. Porto Alegre: Mediação, 2002. p.79-94. MARCELO, C. Pesquisa sobre a formação de professores: o conhecimento sobre aprender a ensinar. Revista Brasileira de Educação, Rio de Janeiro, n.9, p.51-75, 1998. Disponível em: <http://www.anped.org.br/rbe/rbedigital/RBDE09/ RBDE09_06_CARLOS_MARCELO.pdf>. Acesso em: 18 ago. 2009.

MARCON, D. A construção das competências pedagógicas através da prática como componente curricular na formação inicial em Educação Física. 2005. 277 f. Dissertação (Mestrado em Teoria e Prática Pedagógica em Educação Física) - Universidade Federal de Santa Catarina, Florianópolis, 2005. Disponível em: <http://www.dominiopublico.gov. br/download/texto/cp001014.pdf>. Acesso em: 9 dez. 2009.

Construção do conhecimento pedagógico do conteúdo dos futuros professores de educação física. 2011. 574 f. Tese (Doutorado em Ciências do Desporto) - Faculdade de Desporto, Universidade do Porto, Porto, 2011. Disponível em: <http://repositorio-aberto.up.pt/handle/10216/55556>. Acesso em: 24 jun. 2011.

MARCON, D.; NASCIMENTO, J.V.; GRAÇA, A. A construção das competências pedagógicas através da prática como componente curricular na formação inicial em Educação Física. Revista Brasileira de Educação Física e Esporte, São Paulo, v.21, n.1, p.11-25, 2007. Disponível em: <http://www.revistasusp.sibi.usp.br/pdf/rbefe/v21n1/v21n1a2.pdf>. Acesso em: 27 nov. 2009.

MARKS, R. Pedagogical content knowledge: From a mathematical case to a modified conception. Journal of Teacher Education, Washington, v.41, n.3, p.3-11, 1990.

MARQUES, A.M. Formação do profissional da educação. 3. ed. Ijuí: Unijuí, 2000.

MEIRIEU, P. A pedagogia entre o dizer e o fazer: a coragem de começar. Porto Alegre: Artmed, 2002.

MOLINA NETO, V.; MOLINA, R.K. Capacidade de escuta: questôes para a formação docente em educação física. Revista Movimento, Porto Alegre, v.8, n.1, p.57-66, 2002. Disponível em: <http://www.seer.ufrgs.br/index.php/Movimento/ article/view/2637/1263>. Acesso em: 21 set. 2009. 
MONTALVÃO, E.C.; MIZUKAMI, M.G. Conhecimentos de futuras professoras das séries iniciais do Ensino Fundamental: analisando situações concretas de ensino e aprendizagem. In: REALI, A.M.; MIZUKAMI, M.G. (Orgs.). Formação de professores, práticas pedagógicas e escola. São Carlos: EdUFSCar, 2002. p.101-26.

NASCIMENTO, J.V.; RAMOS, V.; MARCON, D.; SAAD, M.A.; COLLET, C. Formação acadêmica e intervenção pedagógica nos esportes. Motriz: Revista da Educação Física, Rio Claro, v.15, n.2, p.358-66, 2009. Disponível em: <http:// www.periodicos.rc.biblioteca.unesp.br/index.php/motriz/article/view/2251/2378>. Acesso em: 1 jul. 2010.

PARK, S.; JANG, J.-Y.; CHEN, Y.-C.; JUNG, J. Is Pedagogical Content Knowledge (PCK) necessary for reformed science teaching? Evidence from an empirical study. Research in Science Education, New York, v.40, n.1, p.1-16, 2010. Disponível em: <http://www.springerlink.com.w10152.dotlib.com.br/content/q2wl21021736558r/>. Acesso em: 19 ago. 2010. PARK, S.; OLIVER, J.S. Revisiting the conceptualisation of pedagogical content knowledge (PCK): PCK as a conceptual tool to understand teachers as professionals. Research in Science Education, New York, v.38, n.3, p.261-84, 2008. Disponível em: <http://dx.doi.org/10.1007/s11165-007-9049-6> . Acesso em: 1 out. 2009.

PERDIGÃO, A.L. Concepçôes pessoais de futuros professores sobre os processos de aprendizagem e de ensino. In: REALI, A.M.; MIZUKAMI, M.G. (Orgs.). Formação de professores, práticas pedagógicas e escola. São Carlos: EdUFSCar, 2002. p.265-94. PÉREZ-GÓMEZ, A. O pensamento prático do professor: a formação do professor como profissional reflexivo. In: NÓVOA, A. (Org.). Os professores e a sua formação. Lisboa: Dom Quixote, 1995. p.93-114.

PERRENOUD, P. A formação dos professores no século XXI. In: PERRENOUD, P.; THURLER, M.G. (Orgs.). As competências para ensinar no século XXI: a formação dos professores e o desafio da avaliação. Porto Alegre: Artmed, 2002a. p.11-33. . A prática reflexiva no ofício do professor: profissionalização e razão pedagógica. Porto Alegre: Artmed, $2002 \mathrm{~b}$. PIMENTA, S.G. O estágio na formação de professores. 5. ed. São Paulo: Cortez, 2002.

Para uma re-significação da didática: ciências da educação, pedagogia e didática (uma visão conceitual e uma síntese provisória). In: PIMENTA, S.G. (Org.). Didática e formação de professores: percursos e perspectivas no Brasil e em Portugal. São Paulo: Cortez, 1997. p.19-76.

PIMENTA, S.G.; LIMA, M.S.L. Estágio e docência. São Paulo: Cortez, 2004.

RAMOS, V.; GRAÇA, A.; NASCIMENTO, J.V. O conhecimento pedagógico do conteúdo de treinadores de basquetebol: uma proposta de investigação qualitativa com treinadores experientes. In: CONGRESSO INTERNACIONAL DE JOGOS DESPORTIVOS: OLHARES E CONTEXTOS DA PERFORMANCE - DA INICIAÇÃO AO ALTO RENDIMENTO, 1., 2007, Porto. Anais... Porto: Faculdade de Desporto/Universidade do Porto, 2007.

REALI, A.M.; MIZUKAMI, M.G. Práticas profissionais, formação inicial e diversidade: análise de uma proposta de ensino e aprendizagem. In: MIZUKAMI, M.G.; REALI, A.M. (Orgs.). Aprendizagem profissional da docência: saberes, contextos e práticas. São Carlos: EdUFSCar, 2002. p.119-38.

SCHINCARIOL, L.M. The types, sources, and perceived relevance of knowledge acquisition, and the enacted effects when teaching unfamiliar and familiar physical education content. 2002. $287 \mathrm{f}$. Doctoral Thesis - Department of Philosophy, The Ohio State University, Columbus, 2002. Disponível em: <http://proquest.umi.com/pqdweb?did=7652 $51041 \&$ sid $=5 \&$ Fmt $=2 \&$ clientId=37541\&RQT $=309 \&$ VName=PQD $>$. Acesso em: 25 mar. 2008.

SCHÖN, D.A. Formar professores como profissionais reflexivos. In: NÓVOA, A. (Org.). Os professores e a sua formação. Lisboa: Dom Quixote, 1995. p.77-91.

SEBREN, A. Preservice teachers' reflections and knowledge development in a field-based elementary physical education method course. Journal of Teaching in Physical Education, Champaign, v.14, p.262-83, 1995.

SEGALL, A. Revisiting pedagogical content knowledge: the pedagogy of content/the content of pedagogy. Teaching and Teacher Education, Oxford, v.20, n.5, p.489-504, 2004.

SETTON, M.G. A teoria do habitus em Pierre Bourdieu: uma leitura contemporânea. Revista Brasileira de Educação, Campinas, n.20, p.60-70, 2002. Disponível em: <http://www.anped.org.br/rbe/rbedigital/RBDE20/RBDE20_06_MARIA_DA_GRACA_JACINTHO_SETTON.pdf>. Acesso em: 21 nov. 2008.

SHULMAN, L.S. Knowledge and teaching: foundations of the new reform. Harvard Educational Review, Cambridge, v. 57, n.1, p.1-27, 1987.

Those who understand: knowledge growth in teaching. Educational Researcher, Washington, v.15, n.2, p.4-14, 1986.

TANI, G. Vivências práticas no curso de graduação de educação física: necessidade, luxo ou perda de tempo? In: SIMPÓSIO DE PESQUISA EM EDUCAÇÃO FÍSICA, 6., 1995, Florianópolis. Anais... Florianópolis: UFSC, 1995.

TARDIF, M. Saberes docentes e formação profissional. Petrópolis: Vozes, 2002.

THIRY-CHERQUES, H.R. Pierre Bourdieu: a teoria na prática. Revista de Administração Pública, Rio de Janeiro, v.40, n.1, p.27-53, 2006. 
VALLI, L.; RENNERT-ARIEV, P. New standards and assessments? Curriculum transformation in teacher education. Journal of Curriculum Studies, Glasgow, v.34, n.2, p.201-25, 2002.

VAN DRIEL, J.; VERLOOP, N.; DE VOS, W. Developing science teachers' pedagogical content knowledge. Journal of Research in Science Teaching, New York, v.35, n.6, p.673-695, 1998.

WOODS, M.; GOC KARP, G.; ESCAMILLA, E. Preservice teachers learning about students and the teaching-learning process. Journal of Teaching in Physical Education, Champaign, v.20, n.1, p.15-39, 2000.

WRIGHT, S. A compatative view of teaching practice in physical education. International Sports Studies, Macao, v.21, n.1, p.55-68, 1999. Disponível em: <http://www.la84foundation.org/SportsLibrary/ISS/ISS2101/ISS2101f.pdf>. Acesso em: 15 set. 2009.

ZEICHNER, K.M. A formação reflexiva de professores: ideias e práticas. Lisboa: EDUCA, 1993.

. Rethinking the connections between campus courses and field experiences in college-and university-based teacher education. Journal of Teacher Education, Washington, v.61, n.1-2, p.89-100, 2010. Disponível em: <http://find. galegroup.com/gtx/infomark.do?\&contentSet=IAC-Documents\&type=retrieve\&tabID=T002\&prodId=AONE\&docId= A216896342\&source=gale\&srcprod=AONE\&userGroupName=ucs\&version=1.0 >. Acesso em: 20 ago. 2010.

\begin{tabular}{r|c} 
ENDEREÇo & \\
Daniel Marcon & \\
Curso de Educação Física & Recebido para publicação: 12/03/2010 \\
Universidade de Caxias do Sul & Revisado: 03/01/2011 \\
R. Francisco Getúliio Vargas, 1130 & Aceito: 30/05/2011 \\
95070-560 - Caxias do Sul - RS - BRASIL & \\
e-mail: drdmarcon@gmail.com & \\
&
\end{tabular}

